\title{
Surveys at a Tibetan antelope Pantholops hodgsonii calving ground adjacent to the Arjinshan Nature Reserve, Xinjiang, China: decline and recovery of a population
}

\author{
William V. Bleis Ch, Paul J. Buzzard, Huibin Zhang, Donghua Xü, Zhinu Liu \\ WEIDONG LI and HoWMAN WONG
}

\begin{abstract}
Females in most populations of chiru or Tibetan antelope Pantholops hodgsonii migrate each year up to $350 \mathrm{~km}$ to summer calving grounds, and these migrations characterize the Tibet/Qinghai Plateau. We studied the migratory chiru population at the Ullughusu calving grounds southwest of the Arjinshan Nature Reserve in Xinjiang, China. The $750-1,000 \mathrm{~km}^{2}$ of suitable habitat at Ullughusu is at $4,500-5,000 \mathrm{~m}$ with sparse vegetation. We used direct methods (block counts, vehicle and walking transects and radial point sampling) and an indirect method (pellet counts) during six summers to assess population density. We also witnessed and stopped two major poaching events, in 1998 and 1999 (103 and 909 carcasses, respectively). Surveys suggested a drop in population density from 1999 to 2000. Poaching was not seen during summer monitoring after 1999, and surveys in 2001 and 2006 suggest that the population density is stable or recovering. We compare the Ullughusu calving grounds with those in the western Kunlun and discuss possible routes for migrating females.
\end{abstract}

Keywords Calving grounds, China, chiru, migration, Pantholops hodgsonii, Tibetan antelope.

\section{Introduction}

The chiru or Tibetan antelope Pantholops hodgsonii is L endemic to the Tibet/Qinghai Plateau, inhabiting remote regions in China and small parts of Ladakh, India. The species once had a vast range, from central Qinghai in the east to Ladakh in the west, and from the Arjin Mountains of Xinjiang in the north as far south as Nepal (Schaller, 1998;

William V. Bleisch* (Corresponding author) and Paul J. BuZzard Fauna \& Flora International-China Programme, Beijing, China. E-mail wvbleisch@ netvigator.com

Huibin Zhang, Donghua Xü and Zhinu Liu Arjinshan Nature Reserve Management, Kuerla, Xinjiang, China.

WeIdong Li Xinjiang Environmental Science Institute, Ürümqi, Xinjiang, China.

Howman Wong China Exploration and Research Society, Wong Chuk Hang, Hong Kong, China.

${ }^{*}$ Current address: China Exploration and Research Society, B2707 Southmark, 11 Yip Hing Street, Wong Chuk Hang, Hong Kong, China.

Received 13 September 2008. Revision requested 13 December 2008. Accepted 12 February 2009.
Leslie \& Schaller, 2008). Despite the remoteness of chiru habitat, however, there was an upsurge in poaching during the 1980 s and 1990 s for its extraordinarily fine wool known as shahtoosh (Wright \& Kumar, 1998). Poaching raised the threat of extirpation for many chiru populations (Harris et al., 1999; Bleisch et al., 2004; Fauna \& Flora International, 2004). Competition with livestock for grazing has been and continues to be a threat and, more recently, infrastructure development, fencing of pasture and gold mining have become increasing problems (Bleisch et al., 2004; Fauna \& Flora International, 2004; Xia et al., 2007; Fox et al., 2009). Chiru are categorized on the IUCN Red List as Endangered (IUCN, 2008), are on Appendix I of CITES and the list of first class protected species under China's Wildlife Law.

Protection and management of the remaining chiru populations require accurate information about ecology, population biology and ranging. Schaller et al. (1991) and Schaller (1998) confirmed reports by early explorers (Deasey, 1901; Rawling, 1905) that much of the total population is migratory and that males and females live separately for most of the year, coming together during the winter rut. Chiru females migrate up to $350 \mathrm{~km}$ from relatively lush winter grounds to high desolate summer calving grounds, and these migrations characterize the plateau ecosystem, just as wildebeest Connochaetes taurinus migrations characterize the Serengeti/Mara ecosystem (Schaller, 1998). Unlike other migrating ungulates, such as wildebeest, saiga Saiga tatarica and caribou Rangifer tarandus, only female chiru migrate to calving grounds (Maddock, 1979; Bekenov et al., 1998; Russell, 1998).

The importance of conserving long distance migrations has received recent attention (Berger, 2004), and here we provide data from the calving ground for one or more long distance migration in chiru. Schaller et al. (1991) and Schaller (1998) traced the summer route of migrating females and were able to estimate accurately the timing of the discrete birth season from late June to the beginning of July. The specific location of a major calving ground, however, was not known until 1992 when HZ tracked large groups of female chiru converging in a remote valley in the western part of the Arjinshan Nature Reserve (Li et al., 1999). HZ then witnessed females giving birth and identified the location of a major calving ground adjacent to the Reserve in the eastern Kunlun 
Mountains. Descriptions of another calving ground in the western Kunlun have since appeared (Ridgeway, 2003; Schaller et al., 2006). We provide a comparative description of the calving ground in the eastern Kunlun from surveys conducted each summer during 1998-2002 and in 2006. We also compare results from a variety of survey methods used and document the detrimental effects of major poaching events that occurred in 1998-1999 (Wong, 1998).

\section{Study area}

The study area is north of the 6,973 m Muztagh Ullugh peak and adjacent to the Arjinshan National Nature Reserve (Fig. 1). The Reserve protects $45,000 \mathrm{~km}^{2}$ in south-east Xinjiang Autonomous Region on the northern edge of the Tibetan/ Qinghai Plateau, straddling the eastern Kunlun Mountains. Since our studies began an area to the west of the Reserve, including the calving grounds, has been included in the new provincial level Mid-Kunlun Nature Reserve. Butler et al. (1986), Achuff \& Petocz (1988) and Li et al. (1999) provide detailed descriptions of the region's geography and vegetation. The climate is continental, dry and cold. Precipitation is rare and sparse, and frequently falls as snow or sleet even in summer. During our surveys summer maximum and minimum temperatures on the calving grounds at an altitude of $4,605 \mathrm{~m}$ averaged 21 and $-3.4^{\circ} \mathrm{C}$, respectively ( $\mathrm{n}=84$ days during 1998-2001). There is permanent snow above c. 5,500 m.

\section{Methods}

In each of the summers of 1998-2002 and 2006 we surveyed the calving grounds for 5-15 days. To assess the density of chiru we used both direct and indirect methodology. Direct methods involved block and radial point counts, and along line transects by vehicle and on foot. The indirect method was pellet counts. We did not include infants in the direct counts because they were often hidden near the groups and were difficult to detect at a distance.

In 1998 block counts were carried out from ridge crests located by a global positioning system, and each block was plotted using topographic features (ridges and peaks). We used binoculars and a 15x spotting scope to locate chiru. Wherever the view was unobstructed, we did not record chiru beyond $5 \mathrm{~km}$.

In radial plot sampling we used a spotting scope to record group size and then estimated the distance from the fixed hilltop observation point to the centre of each group in the sampling area. To assist estimation we located reference points at distances of 1 and $2 \mathrm{~km}$. We began observations at 7.00-8.00 and for c. 1 hour scanned the entire area around the observation point except for the area near our camp, including c. $70 \%$ of the field of view. We used Distance v. 4.1 (Thomas et al., 2003) to analyse data, model the probability of detection and estimate chiru density. We truncated observation distances at 3,000 $\mathrm{m}$, or less where the probability of detection of chiru groups dropped below $10 \%$, and chose the model with lowest Akaike Information Criterion (Buckland et al., 2001; Fox \& Bårdsen, 2005).

We walked fixed straight transect lines in 1999-2001 and 2006. We chose the directional heading of the first walking transect randomly and situated the subsequent two transects at 45 degree increments to the first. On the transects we walked $3 \mathrm{~km}$ recording chiru group sizes and estimating the distances to groups when they were first observed. We estimated distances by eye and calibrated distances $<1.5 \mathrm{~km}$ with an optical range finder. We also recorded the angle of sighting and the observers' heading and then used trigonometry to calculate the perpendicular distance from the

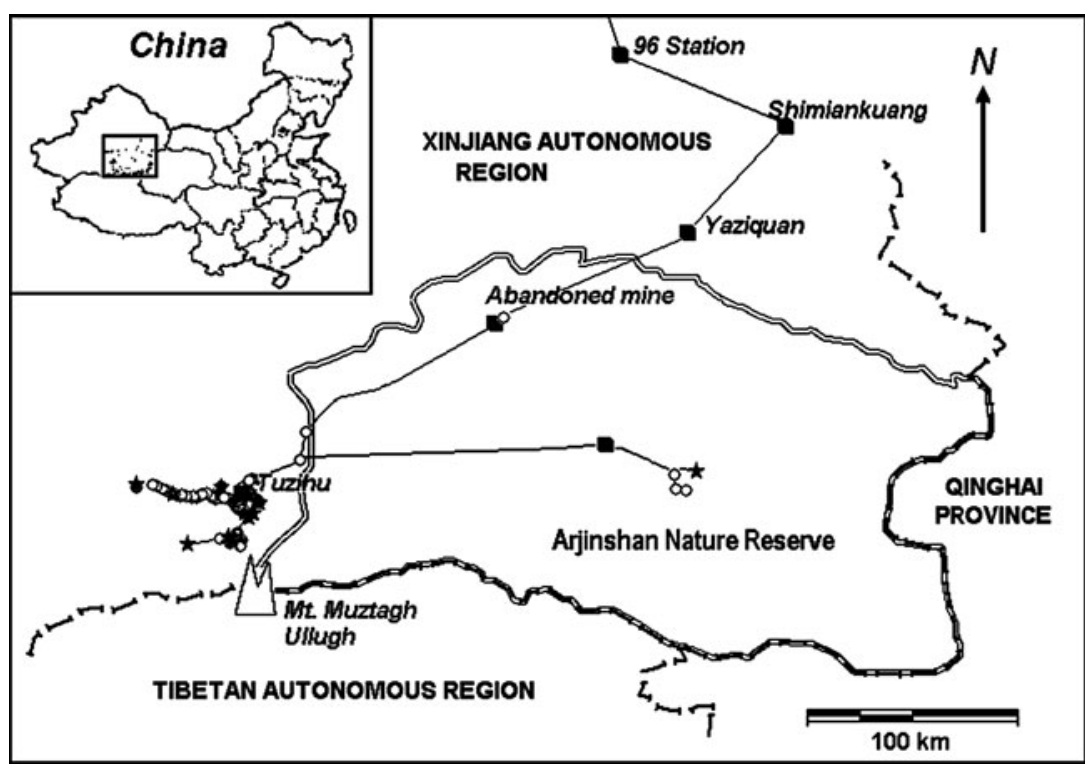

FIG. 1 The Ullughusu chiru calving grounds and surrounding features, showing the survey routes travelled, transect end-points (stars) and chiru sightings (circles). Data for June 2-July 5, 2001, the year when our surveys were most intensive and broadest in coverage. 
animals to the transect line. We pooled data for each year and analysed them using Distance, as with the radial plot sampling.

In 1999, 2001 and 2006 we conducted vehicle transects recording the size of chiru groups and estimated perpendicular distances of groups to the line of travel. Vehicle transects were as straight as possible but changed direction as the terrain required. When possible we calibrated our estimates to distances calculated by the trigonometric method described above. We used Distance, pooling data in each year, to estimate the detection function but taking each day's transect as an independent sample. We could not directly compare the densities among most years, however, because the same transect routes could not be driven every year. In the years 2000 and 2002 we drove transect routes for monitoring purposes and did not estimate the perpendicular distances of chiru groups to the transects. To make comparisons among all years we calculated the index of kilometric abundance (number of chiru seen per km; Brugière et al., 2005) as well as densities estimated based on a $2-\mathrm{km}$ strip width (Schaller et al., 2007).

In 2001 and 2006, after completing the walking transects, we backtracked and recorded the number of chiru pellet clusters from the current year. Current year's pellets, which are dark, are clearly distinguishable from the much lighter previous year's pellets. Since there are chiru present at the site for only c. 1 month each year, the differences are discrete. We measured the perpendicular distance from the centre of the clusters to the transect, including only those pellet clusters within $2 \mathrm{~m}$ either side of the transect, thereby sampling an area of $0.012 \mathrm{~km}^{2}(3 \mathrm{~km} \times 0.004 \mathrm{~km})$.

\section{Results}

The site of chiru calving was located in high elevation valleys (4,500-5,000 m) to the north of Mount Muztagh Ullugh and adjacent peaks (c. $36.5^{\circ} \mathrm{N} 87.3^{\circ} \mathrm{E}$ ) near Rabbit Lake (Tuzihu) in the Ullughusu river watershed (Fig. 1). In the summers of 1999 and 2001 we arrived at the calving grounds on 18 June and observed large aggregations of female chiru already there. We also observed one infant on that date, the earliest an infant was observed during all summer surveys. The last day that a newborn infant was found on any survey was 2 July although surveys continued until 16 July.

Throughout the six seasons of study on the calving grounds we observed only 11 incidents of natural mortality, including two instances of confirmed wolf predation on infants. In 1998 and 1999 we witnessed and stopped large scale poaching events; in 1998, we found 103 carcasses on the calving grounds or along the migratory route just outside the grounds, and we found 909 in 1999.

The highest density calculated from block counts of chiru in 1998 was $21 \mathrm{~km}^{-2}$ (mean 10.1 \pm SD 8.8, $\mathrm{n}=4$; Table 1).
TABLE 1 Estimated density of chiru females from block counts (data for 1998 only).

\begin{tabular}{llll}
\hline Date & No. of chiru & $\begin{array}{l}\text { Estimated area } \\
\text { of block }\left(\mathrm{km}^{2}\right)\end{array}$ & $\begin{array}{l}\text { Estimated } \\
\text { density }\left(\mathrm{km}^{-2}\right)\end{array}$ \\
\hline 26 June & 1,136 & 84 & 14 \\
29 June & 1,397 & 67 & 21 \\
1 July & 123 & 59 & 2 \\
3 July & 272 & 72 & 4 \\
\hline
\end{tabular}

In 1999, 2001 and 2006 we conducted radial point samples from the same observation point each year and were able to match 5 samples from 1999 that occurred on the same day or within 2 days of observation days in 2001. There was a large amount of variation in the number and density of chiru in these years, and no correlation of density between the years (Table 2; Wilcoxon matched pairs, $\mathrm{P}>$ 0.05). We saw larger numbers of chiru in 2006 and there was a significant increase in density from 2001 to 2006 (Table 2; Mann-Whitney $U, \mathrm{P}<0.05$, 1-tailed).

We walked two or more $3-\mathrm{km}$ transects from 20 June to 7 July in 1999, 2001 and 2006. We pooled the data for each year and found that estimated densities suggested a decrease between 1999 and 2001, and recovery between 2001 and 2006 (Table 3). Considering only five matched pairs of transects carried out within 8 days of each other, there was a significant decrease in the number of chiru from 1999 to 2001 (Wilcoxon matched pairs $\mathrm{P}<0.05$, 1-tailed) and a trend of increase from 2001 to 2006 (Mann-Whitney $U$, $\mathrm{P}=0.10$, 1-tailed).

Changes in the number of chiru seen on vehicle transects were consistent with a decline in chiru numbers from 1999 to 2000/2001 and an increase from 2000/2001 to 2002/ 2006 (Table 4). These trends were evident in the indices of kilometric abundance (significantly higher in 2006 than 2001; Mann-Whitney $U, \mathrm{P}<0.05,2$-tailed) as well as in the estimated densities.

The number of chiru faecal pellet clusters were higher in 2006 compared to 2001 (Table 5; Mann Whitney $U$, $\mathrm{P}=0.10,1$-tailed).

The population of females using the calving grounds was large. In 1999, 2,956 individual female chiru were seen in

TABLE 2 Number of female chiru recorded, and densities estimated, from radial point samples.

\begin{tabular}{|c|c|c|c|c|c|c|}
\hline \multirow[b]{2}{*}{ Date } & \multicolumn{2}{|c|}{1999} & \multicolumn{2}{|c|}{2001} & \multicolumn{2}{|c|}{2006} \\
\hline & No. & $\begin{array}{l}\text { Density } \\
\left(\mathrm{km}^{-2}\right)\end{array}$ & No. & $\begin{array}{l}\text { Density } \\
\left(\mathrm{km}^{-2}\right)\end{array}$ & No. & $\begin{array}{l}\text { Density } \\
\left(\mathrm{km}^{-2}\right)\end{array}$ \\
\hline 20/21 June & 310 & 33.9 & 172 & 27.5 & & \\
\hline 22/24 June & 137 & 39.4 & 372 & 32.7 & & \\
\hline 26/27 June & 133 & 6.6 & 173 & 21.9 & 540 & 98.6 \\
\hline 28/29 June & 143 & 11.2 & 336 & 17.8 & 755 & 36.9 \\
\hline 30 June & & & 118 & 5.3 & & \\
\hline 6 July & 214 & 35.1 & & & & \\
\hline
\end{tabular}


TABLE 3 Number of female chiru sighted on three separate 3 -km walking transects $(A, B, C)$ in 1999, 2001 and 2006, and mean densities calculated using Distance v. 4.1 (Thomas et al., 2003).

\begin{tabular}{lcll}
\hline Date & 1999 & 2001 & 2006 \\
\hline 20 June & & $32(\mathrm{~A})$ & \\
25 June & & $10(\mathrm{C})$ & \\
26/27 June & $44(\mathrm{C})$ & $91(\mathrm{~B})$ & $333(\mathrm{~B})$ \\
28 June & $68(\mathrm{~A})$ & & \\
29/30 June & $238(\mathrm{~B})$ & $26(\mathrm{~A})$ & $232(\mathrm{~A})$ \\
2 July & $70(\mathrm{~A})$ & & \\
3 July & $91(\mathrm{~B})$ & & \\
7 July & $405(\mathrm{~A})$ & & 42.0 \\
$\begin{array}{l}\text { Mean density } \\
\quad \text { (95\% confidence }\end{array}$ & 31.0 & 11.5 & \\
\multicolumn{1}{l}{ interval; DCV } & & & \\
\hline
\end{tabular}

${ }^{\star}$ Coefficient of variation of density calculated with Distance

one single $13 \mathrm{~km}$ transect, not including infants. Our most accurate estimate of density was obtained in 2001, of 5.2 chiru km $\mathrm{km}^{-2}$ (Table 4$)$. In that year we surveyed an area of $>750 \mathrm{~km}^{2}$ of suitable chiru habitat in $198 \mathrm{~km}$ of transects, and we estimate that $>2,800$ female chiru, and perhaps as many as 5,500, were present, 2 years after the major event of poaching activity there in the summer of 1999.

\section{Discussion}

The discovery of a major calving ground in a remote location in the Kunlun Mountains to the north of the central migration route of chiru through the Changtang has had immediate implications for conservation of chiru. Poaching or other interference with calving at this site could have far reaching impacts on the population of chiru in the Changtang and on any predators that depend on them. The fact that this calving ground was largely outside any existing protected area when it was discovered in 1992 was a major incentive for establishment of the Middle Kunlun Provincial Nature Reserve in Qiemo County in 2002. The size and importance of this calving population justifies upgrading of the Reserve to national level status. In light of the increasing threats to the western Changtang population
(Fox et al., 2009), protection of this and other populations is imperative.

The character of the calving grounds surveyed resembles the calving grounds in the western Kunlun (Schaller et al., 2006): high, remote from good grazing, with little wolf predation and with sparse vegetation (Bleisch et al., unpubl. data; Li et al., 1999). The timing of calving, with a short season in June and July each year, also matches that described by Schaller et al. (2006).

Determining population size at calving grounds is difficult (Schaller et al., 2006). Frequent movement of animals can cause large daily variation in density estimations, inclement weather often hinders visibility, and many areas are hard to access. Our data, however, indicate that c. 4,000 female chiru used the area in 2001 even after poaching had occurred. These calving grounds are therefore comparable to the calving grounds in western Xinjiang described by Schaller et al. (2006; see also Ridgeway, 2003), which were estimated to support 4,000-5,000 females and are considered to be one of the most important in the species' range. Based on the number of animals that we observed and reports from other regions (Schaller et al., 2007), the Arjinshan calving grounds is an important site and requires active monitoring and effective protection.

Indices of chiru abundance and estimates of density using multiple methods suggest a major population decline at the calving grounds from 1999 to 2001 and a gradual recovery after 2001. Such a decline would be consistent with the widespread anecdotal accounts and reports in the popular Chinese press of poaching occurring both on and off calving grounds before 2001. In 1998 and 1999 the number of newly slaughtered antelope that we observed in the summer alone must have accounted for a substantial proportion of that population's total number.

Our block surveys, point counts and walking transects covered a limited area of the calving grounds, although the sites were chosen to be representative. From the single observation location used for point counts, for example, we could only see the trends in population density that hold for that area and not the whole calving ground. Coverage by vehicle transects was more complete but the counts less robust.

TABLE 4 Lengths of vehicle transects, indices of kilometric abundance (IKA, number of female chiru per km), and estimated densities based on perpendicular distances from the transect, using both Distance v. 4.1 (Thomas et al., 2003) and the fixed strip-width method.

\begin{tabular}{lclll}
\hline Year & $\mathrm{Km}$ & $\begin{array}{l}\text { Mean IKA } \pm \mathrm{SE}, \mathrm{km}^{-1} \\
\text { (no. of transects) }\end{array}$ & $\begin{array}{l}\text { Density using } \\
\text { Distance, } \mathrm{km}^{-2}(95 \% \\
\left.\text { confidence interval; } \mathrm{DCV}^{\star}\right)\end{array}$ & $\begin{array}{l}\text { Density using 2-km } \\
\text { strip width }\left(\mathrm{km}^{-2}\right)\end{array}$ \\
\hline 1999 & 77.3 & $89.2 \pm 48.5(4)$ & $14.2(5.6-36.4 ; 0.49)$ & 16.0 \\
2000 & 131 & $18.2 \pm 13.7(3)$ & $5.2(3.8-7.3 ; 0.17)$ & 1.5 \\
2001 & 197.8 & $9.7 \pm 1.1(6)$ & & 4.3 \\
2002 & 36 & $9.6,29.5(2)$ & $8.4(4.5-15.7 ; 0.33)$ & 3.6 \\
2006 & 50.6 & $24.5 \pm 5.2(3)$ & 5.1 & \\
\hline
\end{tabular}

${ }^{*}$ Coefficient of variation calculated with Distance 
TABLE 5 Chiru pellet densities (clusters $\mathrm{km}^{-2}$ ) from 3 - $\mathrm{km}$ transects (A, B) with a 4-m strip width.

\begin{tabular}{lll}
\hline Date & 2001 & 2006 \\
\hline 20 June & $2,054(\mathrm{~A})$ & \\
$26 / 28$ June & $6,037(\mathrm{~B})$ & $8,000(\mathrm{~B})$ \\
30 June & $6,608(\mathrm{~A})$ & $7,500(\mathrm{~A})$ \\
\hline
\end{tabular}

However, the trends in population density observed with these different methods match relatively well. There are of course potential biases inherent in all of the methods but these biases generally arise from different factors in each method. The comparisons increase our overall confidence that the trends observed indicate real changes in population.

The remoteness of the chiru calving grounds and the difficulties of transportation have made it difficult for researchers or managers to conduct regular monitoring. Our results demonstrate, however, that even under these difficult conditions transect data can be collected in a way that facilitates detection of major population trends. If a monitoring programme of this type had been in place when poaching of the chiru began in the mid 1990s (Schaller, 1998), it is likely that early trends would have shown the impacts of poaching and that there would have been less delay and discussion before major responses were launched to combat poaching and the international smuggling of shahtoosh (Wong, 1998; Wright \& Kumar, 1998). That the decline and recovery of this population could be documented using relatively inexpensive methods suggests a practical approach for tracking future changes in chiru populations as part of the regular work of anti-poaching patrols.

In response to the threat of poaching to chiru survival, anti-poaching efforts were intensified in 2000 (Xi \& Wang, 2004) and work began with international conservation organizations to reduce the international shatoosh trade (Zhen, 2000). Annual summer monitoring at the Ullughusu calving grounds after 1999 did not discover any more poaching, and both direct and indirect indices indicate that the densities of chiru increased between 2001 and 2006.

Poaching and other threats outside the calving grounds may also have influenced this population. We were unable to observe the arrival or departure of females from the calving grounds and hence cannot trace the entire migration route of these females. Numerous tracks and droppings found to the east of the area suggested that many animals arrived from Arjinshan National Nature Reserve, in agreement with local reports of females travelling west to the calving grounds from inside the Reserve. Schaller et al. (1991), however, discovered a large aggregation of chiru in June 1988 in an area north of these calving grounds and west of the Reserve. They counted 377 individuals (a density of $1.4 \mathrm{~km}^{-2}$ ), with a sex ratio of 72 males to 100 females and 25 young to 100 females. It seems possible that some of these females were on route to the calving grounds described here, c. $45 \mathrm{~km}$ to the south-south-east. It is possible that others arrive from suitable habitat to the west. It is also possible that some female chiru migrate to the Ullughusu calving grounds from Changtang in the Tibet Autonomous Region to the south, crossing high passes above 5,000 $\mathrm{m}$ through the Kunlun range. Ruan et al. (2005) found a high degree of gene flow between the Tibet and Xinjiang chiru populations, and noted the importance of calving grounds for increasing this. Welby (1889) and Feng (1991, in Schaller, 1998) described large aggregations of chiru south-east of Muztagh in Qinghai Province, and some of these animals may have been travelling to or returning from the calving grounds described here. However, these chiru could also be associated with another large calving aggregation in the Kekexili region of Qinghai, c. $200 \mathrm{~km}$ east southeast of Ullughusu (Schaller, 1998). Further study should focus on elucidating the migration routes so that they can be monitored and effectively protected.

As long as international demand for shahtoosh remains low and anti-poaching continues to be a government priority, the chiru population may not be faced with the threat of poaching. However, new threats from development, including new mining and linear infrastructures, and impacts of anthropogenic climate change, may have unexpected effects on chiru populations. Monitoring of chiru on the Arjinshan calving grounds and other key populations should continue so that management can respond appropriately to any detected impacts.

\section{Acknowledgements}

This work was made possible with funding from The Kadoorie Charitable Foundations, from Shell Companies in North-east Asia, from the St Louis Zoological Society Field Research for Conservation Program, Pittsburgh Zoo, Columbus Zoo, the Disney Conservation Fund, China Exploration \& Research Society (CERS), Fauna \& Flora International and the generous sponsors of CERS. Encouragement and support was provided by many staff of the Xinjiang Environmental Protection Bureau. Richard Harris and three anonymous reviewers provided invaluable comments on earlier versions of this article. We thank the staff of the Arjin Mountain Nature Reserve and the CERS expedition team for their hard work and companionship in the field.

\section{References}

Achuff, P.L. \& Petocz, R. (1988) Preliminary Resource Inventory of the Arjin Mountain Nature Reserve, Xinjiang, People's Republic of China. WWF, Gland, Switzerland.

Bekenov, A.B., Grachev, I.U.A. \& Milner-Gulland, E.J. (1998) The ecology and management of saiga antelope in Kazakhstan. Mammal Review, 28, 1-52.

Berger, J. (2004) The last mile: how to sustain long-distance migration in mammals. Conservation Biology, 18, 320-331. 
Bleisch, W.V, XU, D. \& Zhang, H. (2004) A cost-effective approach to monitoring and census of wild Tibetan antelope (Pantholops hodgsonii). In Proceedings of the XIXth International Congress of Zoology (eds China Zoological Society), pp. 263-264. China Zoological Society, Beijing, China.

Brugière, D., Dia, M., Diakité, S., Gbansara, M., Mamy, M., Saliou, B. \& Magassouba, B. (2005) Large- and medium-sized ungulates in the Haut Niger National Park, Republic of Guinea: population changes 1997-2002. Oryx, 39, 50-55.

Buckland, S.T., Anderson, D.R., Burnham, K.P., Laake, J.L., Borchers, D.L. \& Thomas, L. (2001) Introduction to Distance Sampling. Oxford University Press, Oxford, UK.

Butler, J.P., Achuff, P. \& Johnston, J. (1986) Arjin Mountain Nature Reserve, Xinjiang, People's Republic of China. IUCN/WWF, Gland, Switzerland.

Deasey, H. (1901) In Tibet and Chinese Turkestan. Longmans Green, New York, USA.

Fauna \& Flora International (2004) A Biodiversity Conservation and Community Livelihood Co-management Plan for the Suojia Area of Qinghai, China. FFI-China, Beijing, China.

FENG, Z. (1991) Wild animal resources in the Hoh Xil region. Chinese Journal of Arid Land Research, 4, 247-253. [in Chinese]

Fox, J.L. \& BÅRDSEN, B-J. (2005) Density of Tibetan antelope, Tibetan wild ass and Tibetan gazelle in relation to human presence across the Chang Tang Nature Reserve of Tibet, China. Acta Zoologica Sinica, 51, 586-597.

Fox, J.L., Dhondup, K. \& DorjI, T. (2009) A review of Tibetan antelope Pantholops hodgsonii conservation and new rangeland management policies in the western Chang Tang Nature Reserve, Tibet: is fencing creating an impasse? Oryx, 43, 183-190.

Harris, R.B., Pletscher, D.H., Loggers, C.O. \& Miller, D.J. (1999) Status and trends of Tibetan plateau mammalian fauna, Yeniugou, China. Biological Conservation, 87, 13-19.

IUCN (2008) 2008 IUCN Red List of Threatened Species. IUCN, Gland, Switzerland. Http://www.iucnredlist.org [accessed 14 February 2008].

Leslie Jr., D.M. \& Schaller, G.B. (2008) Pantholops hodgsonii (Artiodactyla: Bovidae). Mammalian Species, 817, 1-13.

LI, W., LIU, Z., JING, C. \& ZHANG, H. (1999) The natural vegetation of the calving grounds of Tibetan antelope on the north slope of Muztagh Peak, Kunlun Mountains. Xinjjiang Environmental Protection, 21, 9-14. [in Chinese]

MADDOCK, L. (1979) The 'migration' and grazing succession. In Serengeti: Dynamics of an Ecosystem (eds A. Sinclair \& M. Norton-Griffiths), pp. 104-109. University of Chicago Press, Chicago, USA.

RAWling, C. (1905) The Great Plateau. Edward Arnold, London, UK.

RIDGEWAY, R. (2003) 275 miles on foot through the remote Chang Tang. National Geographic, 4, 104-123.
Ruan, X-D., He, P-J., Zhang, J-L., Wan, Q-H. \& FanG, S-G. (2005) Evolutionary history and current population relationships of the chiru (Pantholops hodgsonii) inferred from mtDNA variation. Journal of Mammalogy, 86, 881-886.

Russell, J. (1998) The Nature of Caribou. Greystone Books, Vancouver, Canada.

Schaller, G.B. (1998) Wildlife of the Tibetan Steppe. University of Chicago Press, Chicago, USA.

Schaller, G.B., Kang, A., Cai, X. \& LiU, Y. (2006) Migratory and calving behaviour of Tibetan antelope population. Acta Theriologica Sinica, 26, 105-113.

Schaller, G.B., Kang, A., Hashi, T-D., \& Cai, P. (2007) A winter wildlife survey in the northern Qiangtang of Tibet Autonomous Region and Qinghai Province, China. Acta Theriologica Sinica, $27,309-316$.

Schaller, G.B., Ren, J. \& QiU, M. (1991) Observations on the Tibetan antelope (Pantholops hodgsonii). Applied Animal Behavioral Science, 29, 361-378.

Thomas, L., Laake, J.L., Strindberg, S., Marques, F.F.C., Buckland, S.T., Borchers, D.L. et al. (2003) Distance 4.1. Research Unit for Wildlife Population Assessment, University of St. Andrews, UK.

Wellby, M. (1889) Through Unknown Tibet. J.B. Lippincourt, Philadelphia, USA.

Wong, H. (1998) Sacred birth, violent death. China Explorer, 2, 5-6.

Wright, B. \& Kumar, A. (1998) Fashioned for Extinction. Wildlife Protection Society of India, New Delhi, India.

XI, Z. \& Wang, L. (2004) Tracking down Tibetan Antelope. Foreign Languages Press, Beijing, China.

Zhen, R. (2000) For the Future of Tibetan Antelope. CITES Secretariat, Beijing, China.

\section{Biographical sketches}

William V. Bleisch began working on Tibetan antelope in Xinjiang in 1998 with the China Exploration \& Research Society. His research interests include protection of rare species in China and sustainable development of the Tibetan Plateau. He was China Programme Director for Fauna \& Flora International (FFI) for 20022007. Paul Buzzard was manager of the Tibetan Antelope Project of FFI-China for 2004-2007. Donghua Xü, Huibin Zhang and $\mathrm{ZHIHU}_{\mathrm{HiU}}$ are at Arjinshan Nature Reserve. Huibin ZHANG has participated and organized wildlife surveys in the Reserve since its founding in 1983. WEIDONG Li has researched the taxonomy and conservation of mammals in north-west China, including rare pika species and wild camel. HowMAN WONG is the president of the China Exploration \& Research Society, which he founded to promote conservation of culture and nature in remote regions of China, and he is a Senior Advisor to Arjinshan Nature Reserve. 